\title{
Deficits, Elitism, Fears (DEF) and the Eastern Caribbean English Language Teacher
}

\author{
Stacy. L. Denny (corresponding author) \\ Department of Language, Linguistics and Literature, The University of the West Indies \\ Cave Hill, Barbados \\ Tel: 246-417-4463Ｅ-mail: stacy.denny@ cavehill.uwi.edu
}

Received: July 4, 2015 Accepted: July 23, 2015 Published: October 12, 2015

doi:10.5296/jet.v3i1.8414 URL: http://dx.doi.org/10.5296/jet.v3i1.8414

\begin{abstract}
This is a qualitative research study underpinned by a constructivist philosophy. In this study I collect data by means of questionnaires and interviews primarily. The questionnaire responses however serve as additional voices to the interviews rather than as statistical information. The sample is purposive, comprising 14 questionnaire respondents and 4 interviewees, with whom I sought to explore the challenges they encountered as they taught Anglophone Caribbean students standard English (SE). I also attempted to understand the reasons for these challenges, as well as try to establish, from these teachers, the appropriate strategies for addressing these issues. I discovered that the teachers primarily blame students for the challenges they face professionally; yet irreconcilably, they advocate addressing these challenges by implementing strategies aimed at improving the teacher and teaching. I therefore concluded that between the premises and conclusions teachers make about language learning and teaching lay many contradictions, contradictions which I term DEF, an acronym for issues relating to deficits/diversity, elitism and fear, as well as a pun on the word 'deaf'the inability or unwillingness to hear what contradicts their beliefs about language learning and teaching for fear of processing what the reality might mean.
\end{abstract}

Keywords: English language teaching, Eastern Caribbean, teacher proficiency, teacher training

\section{Background}

This research is the second part of a study carried out in 2008 into matters relating to Eastern Caribbean teachers' language proficiency, entitled "Easy as ABC: Attitudes, Barriers and Contradictions in issues of teacher language proficiency". This first part investigated attitudes exhibited by fourteen Eastern Caribbean teachers from seven islands, towards the coexisting vernacular and standard language in their territories. These attitudes, were argued to have given rise to certain psychological and learning barriers which led to conflicts between language-related theories and pedagogical practices. As a continuation of that research, this 
current study, is aptly titled 'DEF and the Eastern Caribbean English language teacher'. DEF is both an acronym and a pun, which I contend, contributes to the challenges teachers both face and create in the classroom. In this article it is proposed that between the premises and the conclusions these teachers make, sits DEF, issues of deficits/diversity, elitism and fear which are not being adequately addressed, but which require urgent attention if language education is to be more progressive in these territories. In this educational sphere sits another kind of DEF, the inability/refusal to hear what contradicts one's beliefs and values about language learning and teaching. In this work, I will refer to a "space" where there is a meeting of perspectives and interpretations, mine and the participant teachers', and so the research is structured as a discussion between Eastern Caribbean teachers of English and me in the roles of co-discussant and interpreter. Additionally, the literature is weaved throughout the discussion to link the findings that are emerging and ground them in the existing Westernized literature. It is done this way because there is little if anything written specifically about the attitudes of Caribbean English language teachers. For this study, it was important that these teachers have their own voice, separate from the usual Western voice, and so there is no separate literature review which would primarily be serving the Westernised view, simply becauase this is where most of the teacher attitudinal studies have been carried out.

\section{Rationale and Problem Statement}

Improperly addressing the challenges teachers face in helping non-standard dialect speaking students to acquire SE can have serious psychological, pedagogical and language learning implications. In exploring these challenges teachers are being encouraged to confront their own fears and inadequacies, which is a giant step in addressing some aspects of these challenges. For example, if one starts with the premise that teachers have some responsibility for facilitating students' second language acquisition, but are themselves not proficient in the language they teach, then certainly the implications are obvious. It is hoped that through this research, teachers grapple with the painful but obvious implications which are attributable to the challenges they face, and which can ultimately have a deleterious effect on the language education systems in their territories. Therefore, the purpose of this study is to determine the challenges teachers face when teaching SE to Eastern Caribbean non-standard dialect speaking students, to explore the nature, or sources, of these challenges and establish how they can be appropriately addressed. Essentially, this study attempts to construct theory about why these challenges are occurring.

\section{Methodology}

\subsection{Design}

A qualitative research design was employed, undergirded by an interpretive ethnographic approach to collecting the data. According to Smart's (1998) description, interpretative ethnography is a search for meaning about some shared cultural phenomenon occurring in a professional space. In this case, that phenomenon is English language teaching in a primarily non-standard dialect speaking context and the professional space is the language teaching classroom. The idea is to understand how participants themselves interpret these phenomena because "no one knows better than they [members of the community] do themselves; hence 
the passion [of the researcher] to swim in the stream of their experiences (Geertz, 1983: 58). Geertz explains that the researcher seeks to explore life in a professional community, but he says it as though that community were bound by space; that is not the case in my research. In this research, participants experience the phenomenon in different spaces divided by sea and land, but this is all the more appealing in interpreting whether, despite the geographical separations, participants share predominantly similar understandings of their experiences.

\subsection{Participants}

This was a purposive sample. In order to get a depth of understanding of the linguistic issues at stake the sample had to represent teachers of English who were born and raised in the Eastern Caribbean, studied Linguistics, and had three or more years of experience teaching the language. Random sampling would hardly have yielded the characteristics required in a time-efficient way. There were 14 English language teachers (ELTs) comprising the sample. They all had over three years of experience teaching non-standard dialect speakers, and had at some stage studied Linguistics, which assumes a knowledge of the linguistic systems coexisting in their territories. The fact that they are Caribbean born and raised presumes a knowledge of the Caribbean dialects with which their students present, which is important in understanding the expected linguistic challenges students will face in the language classroom.

\subsection{Instruments and Procedures}

Questionnaires, interviews (one-on-discussions) and observations were used to collect the data. The questionnaires (appendix 1) were distributed to fourteen teachers who were either my students at a tertiary institution, or persons I knew professionally in the field of English Language Teaching (ELT). Fourteen questionnaires were administered to teachers who represented seven different islands across the Eastern Caribbean. The questionnaires were either individually handed to the participants on location at the tertiary institution they attended for training, or were emailed to those who were in different islands at the time. On distributing the questionnaire, it was explained to participants what the research was about and why it was important to have their input, but it was also made clear that they were under no obligation to participate. The participants were asked to note their names if they wished to be contacted for an interview. All fourteen questionnaires were returned and each person noted their name; however, a third of the sample was chosen based on comments about which I was curious, those which required clarification and those which merited further probing. As a result, four teachers from the questionnaire process were contacted for a personal unstructured interview (appendix 2). They were really one-on-one discussions as the interactions were slightly different from those of an interview. Ironically, these four teachers were also my students and were physically present for the discussions. There was therefore no need for online discussions. All the discussions were held in my office, a space with which these participants were very familiar, being that they frequented this space as students, and so felt very comfortable to be themselves there. The discussions opened with general small talk and then an explanation as to why she (they were all female) was chosen. The participant's notable comment on the questionnaire was a further point of entry into the discussion. Once an elaboration was offered, as co-discussant, I volunteered an interpretation of what was 
being said, giving an opportunity to the discussant to refute, agree with, or modify these statements. The sessions went on like this for about 15 minutes each. This strategy had a two-fold purpose, to determine if I correctly understood the participant and to evoke a response which merited further exploration through observation and analysis. Each discussion was tape-recorded, as well as notes taken to avoid miscommunication as much as possible. The discussions were transcribed and coded, and along with the answers from questionnaire items, the relevant information was selected to answer specific research questions. What was tape-recorded and transcribed are offered as data presentation; whereas, personal responses (my interpretations and evaluations) are submitted as data analysis.

\subsection{Analysis Techniques}

The answers were coded on the questionnaires and the transcriptions, and then grouped into categories to create smaller more manageable sections of data. They were afterwards cross-referenced with the research questions to match the most appropriate answers/categories to these questions. The anecdotal notes were also used to indicate observations of the verbal and non-verbal behaviour in the discussion fora which could bolster the findings. Sometimes the teachers' interpretations and mine were aligned; other times they were conflicted; nonetheless, both views presented to provide an honest, multi-perspective and more comprehensive explanation of the challenges faced.

\subsection{Limitations}

The questionnaire answers were also interpreted, but admittedly without the benefit and support of further feedback from all the respondents. It was hoped that by selecting teachers from the questionnaire sample this would counteract that deficiency as the current participants would reinforce and extend their own views as opposed to a different sample who might simply be projecting a new set of ideas. Because this is a qualitative study, the focus is not on the quantity of responses, as there is no intention to generalise, so it was more limportant to keep the numbers manageable.

\subsection{Research Questions}

- What challenges do teachers face as they teach English to non-standard dialect speakers in the Eastern Caribbean?

- What factors might be contributing to these challenges?

- What strategies do teachers think should be employed to address these challenges?

\section{Findings and Analysis}

\subsection{Challenges: Overview}

The findings are presented as an amalgamation of teachers' comments from the questionnaires and discussions, as though they were all present as a group at the time of data collection. I felt this brought coherence to the discussion despite the physical separations. It is written as though the teachers themselves are speaking and I am responding by means of an interpretation of what they have said implicitly and explicitly. They are offering their views 
and interpretations of their experiences as ELTs and so I felt the information needed to be reported in their voices, collectively and individually. In this section I present and analyse teachers' views of the challenges they say they face in teaching English to non-standard dialect speakers. According to the majority, respondents and discussants, the primary challenge is with the students themselves; though they are other difficulties related to the teaching of the language, resources, and to the least extent, teachers.

\subsection{Teacher Perspective}

The challenges we face are mainly student-related. The most common difficulty is student deficiency in the language. Students do not read enough; they do not write well or express themselves properly and they lack comprehension in the language because they cannot even transfer what they learn in grammar to writing compositions. If that were not enough with which to contend, their vernaculars interfere with their acquisition of the native language, English. In addition to all of this, they have a bad attitude to learning the language. It seems that they have formed mental blocks to the language, so we as teachers cannot get them to accept the importance of learning and using it. Furthermore, they are unwilling to practise the required structures and are reluctant to accept correction. These students lack interest because they think the language is difficult and we simply cannot motivate them.

There are other difficulties we face relating to the language itself, along with some resource issues. For example, there are too many grammatical rules to teach and so it is difficult to get students to understand grammar, that is, the transferring and applying of the rules such as subject verb agreement, especially in certain content areas. English is after all, a difficult language to teach. With regard to the resources, many teachers will tell you that there are not enough texts and there is also a lack of adequate supplementary resource material for teachers. Further to this lack, much of the material is not even culturally relevant, and the texts do not relate to the academic level of the children.

Only a small minority of teachers are part of the problem. It is true that a few teachers do not have knowledge about the correct and appropriate grammatical structures or they do not know which concepts to teach first or what methodologies to use. I know of only one teacher who said that she needed more training to teach the language. Many will never openly admit this, and so what we find as teachers at the upper levels is that we have to re-teach concepts because students were badly taught by some teachers in the lower levels.

\subsection{My Perspective}

If we cannot change a situation, perhaps we can adjust our attitude to it. I believe based on what I am hearing and seeing, that this adage correctly applies, still, I think that as teachers you have the power to change some of the situations in which you find yourselves. As I hear you all speak, two thoughts automatically form. Firstly, teachers can easily fall into the habit of complaining because there is so much wrong with the system and the rewards seem so minimal. The issue for me however is the defeatist attitudes you appear to be adopting ("we simply cannot motivate them"). Certainly, such pessimism, however merited, must translate into a less than enthusiastic pedagogical practice, so that the students you are supposed to be 
helping can easily become the target of this despondency without your awareness. This attitude must also tell on the professional esteem of you as teachers, who, unable to motivate your students, must begin to feel unsuccessful at your jobs. This combination of despondency and lack of results could bring about serious self-doubt as professionals. What though if you were decidedly more positive in your professional outlook? One researcher for example believes that teachers "with...positive attitudes may be the most important key to the success of all types of students" (McLeod, 1994: 37). I wish to add here to their own success as well. In spelling out these attitudes, McLeod refers to a study conducted by Garcia (1991) regarding effective school practices for language minorities in the US. In it, Garcia identifies teachers who encourage communication among students, those who organise instruction around students' interests, are proud of their students and reject concepts of academic, linguistic, cultural and intellectual inferiority. Is this truly our disposition when we walk in and out our classrooms; are we engaging in these effective practices? Our attitudes as teachers might very well go a long way in tackling the issues, or not tackling the issues, we face which hamper student and professional progress.

Secondly, I do not think that as teachers you have sufficiently owned up to your role as contributors to the challenges you face. For instance, when you view a child's language as having little value in their own education by saying that it interferes, this is problematic. I completely understand the views that are shaping this thinking. They are no different from other teachers' around the world who teach in bidialectal and multidialectal classrooms. The National Council of Teachers of English (NCTE) (1965) Task Force observers for instance, speak to this same attitude of teachers who believe that students' dialect should be fully accepted in school, whatever that means, for students were observed constantly being encouraged to speak "properly", but SE should be the focus. Think about what we are saying and doing. We are saying, I accept your dialect in school but do not speak it here because it is improper. This is illogical. Our theories and practices are at odds. I understand that you take this position because you believe that SE is "necessary for greater social and job mobility by disadvantaged students with a strong regional or racial dialect" (NCTE, 1965: 89). We must not forget however, that in the process of helping our students become upwardly mobile, we are also assisting them in becoming self-confident, well-balanced and cognitively complex beings. These are the qualities necessary for success and in taking away their language from any sphere of their lives we are depriving them culturally and linguistically. In fact, the NCTE (1965) forcefully acknowledges this when reporting: "The greatest deficit, and threat to academic achievement of the disadvantaged child is his retardation in the development of [his/her] language and conceptual skills" (p. 72). Any child who is denied the opportunity to develop literacy and cognition in his/ her own language will hardly have the proper foundation for second language development.

Our view of language education in this part of the world is perhaps our greatest challenge. Unfortunately the legacy of education left us by colonialism remains firmly intact. The practice of educating non-standard dialect speaking children is that of topping up a shortfall. It is predicated on the view that these students are linguistically deficient, rather than different, because they do not possess English. This outlook on the part of educators has led to 
discriminatory practices. For example, Bartolomé (1994) cites studies which show the link between teachers' deficit orientation and discriminatory practices (e.g. Anyon, 1988; Bloom, 1991; Lareau, 1990). It was particularly interesting that teachers seemed genuinely unaware of the role they played in the "differential and unequal treatment of their students" (Bartolomé, 1994: 203) Putting the blame or the responsibility of learning English squarely on the shoulders of children exposes the flaws of our supposed adult thinking regarding language teaching. Take for example, as Eastern Caribbean teachers, we argue that we should not teach the non-standard, or through it, because students already know this language. If we follow this reasoning through to its logical conclusion then, the fact that many of us teachers think that SE is the native language of these territories would imply that students already know SE, so that if the act of knowing bars the act of teaching, then neither should we teach SE nor through it. More baffling though is the fact that SE is seen as our NL, but we complain that the "native" children do not know it. Is it easier to premise that SE is our native language and conclude that most of those born into this language situation do not know their own native language; and hence, something must be wrong with the people born into this situation? Or is it not simpler to premise that SE is not our NL; hence, the reason it does not come naturally to most born into this linguistic situation? The real challenge seems to be our deficit view of language education compounded by a lack of sociolinguistic, formal linguistic and pedagogical understanding of the bidialectal situation in which we operate, which translates into serious incongruities between our personal/professional theories and pedagogical practice.

Additionally, as professionals and adults, it is unfair to primarily blame student motivation for what is obviously a very complex situation. It is our responsibility as teachers to motivate our students in the classroom. If we do not fulfil that responsibility, how can it be their fault but still be our responsibility? It is illogical. Interestingly, when McLeod (1994) conducted her own research into the issue, unlike this study, insufficient student motivation was listed as one of the least challenges U.S. teachers cited in educating linguistically diverse students. The fact is, our students come to school with a language that is different from the school language. Additionally, they present with varying levels of proficiency in English, and teachers feel pressured, real or perceived, to help each student to a required level of proficiency, according to attainment targets, by the end of the school year. A poor result reflects negatively on the teacher. This task is not only difficult; it is stressful. It is made even more stressful when linguistic diversity is seen as an obstacle to effective language teaching rather than an interesting linguistic challenge which opens up the possibility of creating order out of potential linguistic chaos. In fact McLeod (1994) notes that a more significant obstacle than linguistic difference is the disparaging way in which these differences are treated. Such negative attitudes about students' language might be demotivating students in the language process because this type of discrimination "can be felt as deeply as racism" (McLeod, 1994: 32). The child's vernacular now becomes the target. It is seen as the obstacle to target language acquisition. Yet again, the reality is that as teachers we cannot change the language with which students present, so we should not make issues, over which we have no control, the controlling issues, because then the issues automatically triumph. Frankly, what I am seeing here beneath the surface is an inability to motivate due to an inability to innovate. Perhaps the Task Force of the NCTE (1965) makes it clearer from their observations that: 
the average teachers are superficial in their approach, and consequently what they personally and professionally perceive in life is commonplace and meaningless to the...disadvantaged student...it would appear that the teacher who has philosophical insight enough to extract the human elements from life...is the most effective teacher of the culturally disadvantaged (p.139).

The task force is here speaking of teachers and students who are perhaps from different cultures and races, but you have the advantage, for the most part, of being able to wholly identify with your students, as you look like them, you can speak like them and you, in most cases, come from right within their communities. You are them, and this is what you need to capitalize on if you are to have them align themselves with you in the classroom. That feeling of oneness, as if you are rooting for them will motivate them. Hardly will their motivation be intrinsic for learning a language they do not know or more importantly, know why they should. We have to take a large part of the responsibility for extrinsically motivating them, particularly in the beginning stages of language learning.

Fear of facing our personal deficiencies is a challenge which can prove professionally paralyzing. You seem to find difficulty in placing yourselves within the centre of the issues, which perhaps make it difficult to assume responsibility for some of what is wrong with the system. We cannot tackle the issues if we do not see the parts we play, if we do not know or understand our position on them and certainly if we do not feel ourselves a part of these issues. For example, you admitted, through clarification, that some teachers are responsible for reinforcing incorrect language concepts in the classroom because that was what they were taught and in some cases they do not know better or differently; so you excused their deficits without linking them to the challenges in the system. An example of this is expressed by one of the participants:

when I did my research for my Caribbean studies project, I (inaudible) that a lot of teachers they do believe that they are competent in standard English (I: uh uh) but when they actually teach in the classroom...they do in fact revert to creole English....and I believe that the teachers now are somehow reinforcing the...reinforcing Creole English rather than reinforcing standard English' (SL2).

Do you notice that she never explicitly says that this is a problem and why? I understand that it must be difficult as teachers of the language to admit that we are reinforcing something other than English. We are being paid to be proficient in the language, as a pilot is being paid to be proficient at flying. However, the real issue becomes one of how professionally ethical it can be to know that we as teachers, or our colleagues, are not linguistically or pedagogically sound in the language we teach, but remain in the system offering mediocre service for years when there may be much potential for excellence buried within us were we to seek out the appropriate training. Can we imagine the damage done in that span of time, versus a teacher who acknowledges the weakness and gets the needed help? Even the level of confidence must be affected in such a way that more proficient teachers feel more competent to tackle the challenges they face. When teachers are well-versed in their specializations, they "own their knowledge" says Bartolomé (1994: 200), and in so doing, they gain confidence, 
which can help translate theory into practice. I believe that we need to "own" our lack of knowledge too and for this reason I laud the only two teachers who accepted responsibility in the discussion for contributing to some of the challenges they face. They say:

I needed more training...[I] do not know which concepts to teach first...In terms of speaking perfect English, I don't think I could probably...ever would (SV3).

I don't really speak the English well, as in the sense that my grammar is very poor... I...well having been at university I recognise that my problems were in the subject verb agreement and it doesn't only comes (sic) out when I'm speaking but even in my writing (SV1).

Ironically these are the only two in the questionnaire who admitted to lacking proficiency in English. Their awareness already puts them at an advantage in terms of wanting to do better and seeking out ways to improve.

\subsection{Summation}

If one is not part of the solution, one might be part of the problem. What I am seeing here is that teachers are not intimately knowledgeable about the issues relating to language diversity and variation within their communities or classrooms. For example, there is a lack basic sociolinguistic knowledge which greatly influences their practice, such as the difference between native language and national official language. This is unfortunate when considering that they took Linguistic courses. Obviously, knowledge does not automatically translate into understanding or practice. They seem unaware that they operate in bidialectal communities in real life as they attempt to enforce monolingualism in the classroom. When practice ignores linguistic reality there are bound to be serious conflicts. In addition to a lack of linguistic understanding, teachers do not appear to possess the technical know-how to address the issues surrounding bidialectalism. These limitations, coupled with misinformation about the coexisting languages, lead to incompatibilities between what teachers theorise about student linguistic knowledge and what teachers expect in terms of student language outcome. This can easily draw up feelings of frustration which lead to pessimistic attitudes and perhaps the defeatist stance I believe these teachers have adopted without realising it. Over and above this all, the profession of teaching is highly respected in the Eastern Caribbean, as it is a marker of intelligence, so that by removing the veneer, serious issues might be uncovered that teachers, educational systems and entire communities would rather not discuss. Regardless, if teachers know they have certain weaknesses which could impact their jobs, they should feel morally and professionally obligated to seek out the required assistance. The challenge of seeking help now, becomes a challenge of giving students help later.

\section{Contributing Factors}

\subsection{Teacher Perspective}

Undoubtedly, students' home environments are the major contributing factor to the challenges we face in schools as teachers. Students are not given the necessary encouragement to want to succeed in school, as parents do not help with homework; there is 
no reinforcement of SE in the home, and so all that children learn at school is quickly forgotten by the next day and then we as teachers have to start the process of reinforcement all over again. Another serious factor relates to the interference of their mother tongues in the acquisition of SE. Children write like they speak and because their speech is dialectal, they tend to write poorly. Also, a lot of these children have very poor self-esteem in general but especially regarding learning and academics. The nature of SE is also a contributing factor, as the language is very complex with many exceptions to the standard rule, which makes it difficult to teach and retain. Finally, the dearth of socially and age appropriate Caribbean texts means a reliance on Westernized texts which are not culturally relevant to the students and therefore they might find them difficult to engage with.

\subsection{My Response}

If I am to understand you correctly I can summarize your views in the following way:

Table 1. Teacher challenges and sources

\begin{tabular}{|c|c|}
\hline Challenge & Source \\
\hline Students' motivation & Home environment \\
\hline Poor language arts skills & Vernacular influence \\
\hline Poor self-esteem & No source given \\
\hline Teaching SE & Complex nature of the language \\
\hline Lack of resource materials & Dearth of culturally relevant materials \\
\hline
\end{tabular}

I want to start by saying that it is professionally irresponsible to blame a child's home environment for his failing academic achievement. We have no real jurisdiction over that domain. While the home will have some influence, teachers are primarily and professionally charged with helping students succeed academically, particularly at the elementary levels. We can seek ways to make better home-school links to increase chances of better success, but we do not negate our responsibility by saying that it is the fault of the home as to why these children are not succeeding academically. Whether we approve or not, school and academics are our primary domains as teachers. If we blame the home, over which we have little control, we are in fact saying that these children are a lost cause. We might even be implying that children can only succeed if they come from advantaged environments, and unwittingly, we support and promote an education aimed at the middle-class, fluent SE speaker. When we primarily focus on the home, we are failing to see the other contributing elements. It is very possible that we are designing and executing language curricula for mostly non-existent students, because we start with what we want them to become rather than as who they come. This is not practical. McLeod (1994) explains this implicit policy we as Caribbean teachers have adopted, though she is in fact "calling out" US policy officials in saying that "[d]espite the increasing linguistic diversity among students attending U.S. schools, education reform proposals...have been addressed to the 'universal' student, who is assumed to be a fluent, native speaker of English with a European American cultural background" (p. 9). Scott and 
Smitherman (1985) offer a different dimension which widens the scope of the debate. While McLeod (1994) focuses on race and culture, they speak to the politics of socioeconomic class, which I believe shapes our views of language education as Eastern Caribbean teachers more so, because race may be less of an issue, or perhaps a more dormant issue in these parts. I dare us to see where we stand in light of their very revealing comments:

\begin{abstract}
Based on the premise that the...child's home environment ill prepared her/him for equal participation in the school culture and recognizing that the school culture was based on middle class norms, compensatory education programs attempted to prepare the student to be middle class, thereby preparing the student for the school culture....In a pedagogy founded on the premise that ...students must imitate the language patterns and language behaviors of middle-class children in order to benefit from instruction in the schools, teachers could very well be expected to model their instructional programs and their teaching styles accordingly (Scott \& Smitherman, 1985: 307-308).
\end{abstract}

It is possible that our pedagogical programmes are not aimed at the students who sit before us and so we can only see them as the failure. When we play the blame game, the children will ultimately lose. We set them up for failure by citing all the reasons why they are unlikely to succeed, reasons, which for the most part, are outside of the child's control. We cite their home environment, their vernaculars and their inability to understand the school language. They cannot change these things. The reality is that these students lack sufficient proficiency to succeed in English medium classes, and they need help to overcome this obstacle (McLeod, 1994), so there really is only one question we should be asking as teachers: What form will this help take on my part? If this help is in the form of unwittingly making students feel defective, then they do not need this type of help because " $[t]$ he motivation of students can be dampened...by the low expectations of teachers" (McLeod, 1994: 31). In essence, what appears on the surface as an absence of internal motivation or home assistance, might very well be, if we dig deeper, a presence of external demotivation from the school environment.

The L1 interference theory promotes flawed thinking and supports unsound pedagogical practices. As long as two languages are coexisting there will be cross-lingual influence. It is really a question of how much of that influence is really interference as opposed to strategies students use about what they already know to help them acquire what they do not know. Essentially, I am suggesting that there might very well be another plausible perspective besides dialect interference. The argument introduced by this theory leads us to think that only non-standard dialect speakers make the kinds of errors that we observe in their speech and writing and so the vernacular must be the cause. This could not be farther from the truth, as research shows (Dulay \& Burt, 1972; Brown, 1973a, b; Winch and Gingell, 1994) that native speakers who have no links to the non-standard make the same errors with which our students present. Dulay and Burt (1974), some of the pioneers of child second language acquisition work, plainly state that studies in this field show "that errors children make while learning certain structures of English as a second language are similar to those made by children learning English natively" (p. 130). How do we then explain this phenomenon? In adhering to the view that the vernacular is a source of interference we perpetuate the colonial 
view of good and bad language, which reinforces the deficit model of language education. The model says that these children's linguistic lack is closely linked to their sociocultural disadvantages and so they come to us wanting and we need to top them up linguistically. When we buy into this view, we do not see what the children do bring to the language learning table which could be of value in the learning process. Bartolomé (1994) is of the view as relates to this subject, that "our deficit orientation towards difference, especially as it relates to low socioeconomic groups, is very deeply ingrained in the ethos of our most prominent institutions, especially schools..." (p. 203). Our natural response therefore is to fill them with English, because the "overriding assumption that learning English will lead to achievement has led educators to focus on teaching English and testing English proficiency" (McLeod, 1994: 14) but in fact says Moll (1992), this assumption impedes learning because we focus on how much English the learner knows as opposed to how much the learner knows in general which could help him/her learn English and succeed in the classroom. When we find out what students know in terms of content we can use more meaningful assessments besides linguistic proficiency (Moll, 1992). We have fallen into the trap whereby "[1]earning English, not learning, has become the controlling goal of instruction...even if it places the children at risk academically" (McLeod, 1994: 14). In the Caribbean settings, students can easily explain what they know about a topic in their vernacular. As most teachers speak the same dialects this can be used as a basis for the English language class, rather than have students withdraw from the discussion because they do not have the appropriate school language (Denny, 2002).

Citing difficulty in teaching SE because of its nature really speaks to the teaching methodology not the language. To say that you find SE difficult to teach because it is a difficult language is a circular argument. All languages are complex linguistic systems. Would we for example argue that Mandarin is less, more or equally difficult to learn/teach than English? It depends on whom you ask and from where they sit. In short, these judgments are relative. Language learning/teaching is a complex process and this is why we are cautioned by Bartolomé (1994) "against the general tendency to reduce complex educational issues...to mere "magical" methods and techniques designed to remediate perceived student cognitive and linguistic deficiencies" (p. 201). In other words, there is no simple way to teach any language, but there are certainly wrong ways. When I hear you speak about ELT I hear about the rules of grammar. Saying that it is difficult to teach due to its many rules suggests that you are still stuck in the traditional unhelpful mode of teaching language as a set of grammatical rules rather than as a communication system where the focus is on form and function in context. Like you, the NCTE (1965) task force found "teachers who were stressing the traditional schoolroom grammar approach admitted that students seemed unable to remember the most basic grammatical rules and definitions" (p. 122). Perhaps students find it difficult to retain the information because there are unreasonably too many decontextualized rules to remember and so when they leave the classroom they cannot make the connection between the rules of the language and real life. The language has to be taught in a meaningful context if it is supposed to matter to the learners and be retained for future use. Again, we may very well be focusing our energies on the nature of things which we do 
not have the power to change; whereas, our energies could certainly be better spent on the things we can change.

The grammatical approach also underscores a view of language teaching inconsistent with what is happening in the real world. This view emphasizes language as a set of grammar rules rather than as a communicative system relevant to the social functions of real life. The issue might very well be how we are trained to view language and language teaching as opposed to the nature of the language itself, which we cannot change anyway. In the Eastern Caribbean, based on my observations, teachers' methods of teaching English using native language methodology is sure to exacerbate the issue as they teach as though students already have a good handle on the language. This type of instruction sees teachers taking the lead and focus by explaining, discussing, quizzing and assigning homework (McLeod, 1994) rather than engaging, interacting, encouraging and stimulating talk. Many children will find the former approach boring to say the least, so what we may term as disinterest might simply be disconnect, as students cannot relate to what is happening and resign themselves to the idea that it is therefore not relevant in their worlds. Your response is by no means uncharacteristic, though it really speaks to a lack of training as to how to deal with the teaching of SE in a bidialectal context. I reiterate, that yours is certainly not a singular case, as McLeod (1994) in divulging communication with Ramirez in 1992 reports that Ramirez says that most LEP students receive most instruction from monolingual English speaking teachers who lack special training in second language teaching. Consider then, that the pedagogical approaches on which we draw, due to a lack of specialized training, and hence, a knowledge of viable alternatives, rather than the nature of the language, could be hampering our students' linguistic and educational progress.

\section{Strategies}

\subsection{Teachers' Voices}

There are two main strategies we can use to address the problems we face in teaching SE to non-native speakers. Firstly, there needs to be changes in policy and classroom practice. More specifically, our governments need to look more closely at the entry requirements for the teaching service along with testing teacher language proficiency through some monitoring programme to ensure they know the language. In relation to changes in classroom practice, we need to use more practical methods that take the dialect situation and the culture of the community into consideration. At least one of us believes that the Language Arts curriculum should be revised to reflect the linguistic situation in the country and it should contain certain strategies and activities that incorporate the students' first language to help them acquire the standard language. We also agree that pedagogical changes should include more oral activities in the classroom, as well as writing activities that give students practice in the use of the language, and encourage them to take responsibility for their own learning, such as writing logs, portfolios, journals and reports. The idea is to make the teaching of English fun. Secondly, besides changes in policy and practice, there also needs to be improvement at the level of training and resources. We believe that teachers should be trained in special fields to enhance the level of English in schools, so, for example, there could be training for literacy 


\section{Macrothink}

specialists or simply training for the teaching of English through engagement in workshops, so that teachers can be better enlightened about the teaching of English. With regard to the resources we would like to see an improvement in terms of the amount made available to us, especially in terms of texts, and also in respect to their cultural appropriateness.

\subsection{My Voice}

\subsubsection{Targeting Deficits and Diversity}

Again, if I am interpreting your views correctly the summation below should be adequate.

Table 2. Teacher challenges, sources \& strategies

\begin{tabular}{|c|c|c|c|}
\hline Challenge & Source & Strategy & Elaboration \\
\hline $\begin{array}{l}\text { Student } \\
\text { motivation }\end{array}$ & $\begin{array}{l}\text { Home } \\
\text { environment }\end{array}$ & $? ?^{*}$ & \\
\hline $\begin{array}{l}\text { Poor } \\
\text { language arts } \\
\text { skills }\end{array}$ & $\begin{array}{l}\text { Vernacular, don't } \\
\text { read }\end{array}$ & $? ?$ & \\
\hline $\begin{array}{l}\text { Poor } \\
\text { self-esteem }\end{array}$ & $? ?$ & $? ?$ & \\
\hline Teaching SE & Nature of SE & \begin{tabular}{|l|} 
Change in policy \\
$\begin{array}{l}\text { Change in teaching } \\
\text { practice }\end{array}$
\end{tabular} & $\begin{array}{l}\text { Review entry requirements for } \\
\text { ELT } \\
\text { Test teacher linguistic } \\
\text { proficiency } \\
\text { Monitor teacher proficiency } \\
\text { Revise language curriculum } \\
\text { Use of more practical methods } \\
\text { - Incorporate native } \\
\text { - language in lessons } \\
\text { - Incorporate native culture } \\
\text { Focus more on oral } \\
\text { - Uctivities } \\
\text { Use more fun writing } \\
\text { activities (logs, portfolios, } \\
\text { journals etc.) }\end{array}$ \\
\hline $\begin{array}{ll}\text { Lack } & \text { of } \\
\text { resources } & \end{array}$ & $\begin{array}{l}\text { Dearth of } \\
\text { culturally } \\
\text { relevant materials }\end{array}$ & $\begin{array}{l}\text { School authorities should } \\
\text { make more available and } \\
\text { ensure they are culturally } \\
\text { relevant }\end{array}$ & $? ?$ \\
\hline$? ?$ & $? ?$ & Specialist training & $\begin{array}{l}\text { Training in literacy and } \\
\text { specifically ELT }\end{array}$ \\
\hline
\end{tabular}

*?? None identified. 


\subsubsection{Content Knowledge Training}

Eastern Caribbean ELTs must be knowledgeable about the language they teach and the primary vernacular of their students. I am not insinuating that as a whole they do not know English, but that some do not understand the linguistic make-up (how it is structured, how it functions and why it functions this way and where it functions most appropriately) of the language well enough to be teaching it. No teacher of English should be mediocre in the use of the language when they are professionally entrusted with the task of making a society literate and proficient in that language. This means that they must be the most proficient models for the rest of the society. After all, a 'thorough deep understanding of the content contributes to teachers' ability to represent and deliver that content in various ways' (Irvine, 2003: 46). Conversely, a lack of subject matter knowledge can negatively influence not only what is taught, but how it is taught. For example, if teachers see the language only as a system of rules, they will perhaps be formulaic in their approach, relying on outdated methods of teaching language as grammar rules. However, if they see the language as a tool for communication, expression and negotiation, the classroom activities would reflect more communicative approaches to learning. Our ELTs should also have linguistic knowledge of the non-standard variety with which their students present, so that they can identify and illustrate the difference between deviation from the standard, i.e. poor grammar of English, and use of the non-standard dialect. Understanding these contrasts can mean the difference between reinforcing incorrect and correct English grammar in the classroom, as teachers would be mentally aware of what constitutes the rules of English and what constitutes the rules of non-standard English, and they would know that a deviation of the standard rule is not necessarily synonymous with nonstandard rule application. When teachers begin to grasp the linguistic structures of these languages they begin to have a better appreciation for the nonstandard as a rule governed linguistic system like the standard, which can be a useful resource in the classroom.

Essentially then, one of the primary qualifications for hiring ELTs in this context should be knowledge and training in the coexisting languages. As a result, subject matter knowledge should become a top priority for hiring an ELT as the Campbell et al (2000) study found while investigating various standards for teaching across America. The INTASC report (Interstate New Teacher Assessment and Support Consortium), developed by the California University, explains subject matter knowledge to mean that the teacher should understand 'the central concepts, tools of inquiry, and structures of the discipline(s) he or she teaches' (as cited in Campbell et al., 2000: 4). They refer to central concepts, those which are fundamental to understanding the subject; hence, basic knowledge would never suffice as a criterion for English language teaching. This requisite knowledge and training should not be trumped by the number of certificate passes persons have in regional exams or if they have a degree of any sort. I wholeheartedly agree with you that this kind of teaching must involve specialist knowledge and training. This profession can no longer be seen as a "free for all" pass. 


\subsubsection{English Language Proficiency Training}

In addition to knowing about the language, teachers must know the language and how to use it proficiently. Unfortunately some of our teachers are not proficient in the use of English (Denny, 2010). While I think formal Linguistics training is vital for language teachers, it is equally important that ideally they become highly proficient in the use of the target language before they are pedagogically trained. Ideally, only when teachers reach an acceptable level of proficiency (determined by standard Boards) should they be allowed to teach the language. We can only get out of the system what we put in. If we allow poorly proficient teachers into the system, what can we expect in return? On this issue, Strickland (1998: 126) forthrightly notes, 'it is absolutely necessary for the teacher to understand the subject he is teaching. He cannot teach arithmetic if he can't add. He can't teach reading if he is barely literate. He can't teach children to write if he can't write properly himself'. I do not think that many would refute this logic, and I wish to add here that complete incompetents are generally not the type of teachers who enter the system, but mediocrity will not suffice either. We cannot expect high levels of success if we give a pass to teachers with mediocre/average linguistic proficiency in the language which they teach. If we want the best returns from the system, we have to put the best into it. By no means am I saying that the best cannot be crafted within the system; that is entirely possible, as people's potential develop at different rates; however, what I am candidly saying is that when we see no effort for improvement over the years (discerning attitudes) then that person is perhaps not in the right profession. It is my view that teachers should be taught and re-taught in the use of the language before they can be properly assessed, and some record kept as to their progress or non-progress (General Accounting Office, 2003). ELTs must therefore be regularly tested against an approved national, regional and international proficiency standard; not as a way of demeaning them, but as a means of upholding them to the highest professional standards.

\subsubsection{Affective Training}

Training ELTs must go beyond merely filling teachers' heads with knowledge to make them theoretically "intelligent". In short, "raw intelligence is insufficient for accomplished teaching" (Berliner, 2000: 358). This being said, there is no doubt in my mind that a teacher should be among the most highly knowledgeable and trained professional in the world, as their lives intersect with that of every other existing profession. Nevertheless, the kind of language education training we require in the Eastern Caribbean must strip away the layers of misinformation about socially imposed views of language and teach teachers about language as neutral linguistic systems, as communicative systems and codes which are excitingly challenging to crack. This kind of training needs to work at reversing the thinking that "the language [nonstandard] is a barrier in the educational process" (Scott and Smitherman, 1985: 312 ), and rather encourage teachers to see that the barrier is the result of "the stigma attached to it, the lack of respect given to it, and the lack of knowledge about it" (ibid.). I think one of your colleagues from Barbados expresses this sentiment well in referring to appropriate teacher training to counteract negative language attitudes regarding the nonstandard: 
...teach them really what Linguistics is...so that to me in really looking at it now all teachers should really do a course or two in Linguistics...because they're a lot of things coming to light daily along with research and so on being carried out that teachers can benefit from. Because to me if they really understood language and how children learn language then we would be better able to understand the difficulties they face. Now that I have done some courses here and I understand now really that I...looking at vocabulary wrong and spelling and so on wrong I try to make improvements in composition. We've started doing it differently and I've found the results are...I...they have actually increased almost I can say almost probably 80 fold where I have eighty percent where I have students running me down now 'when are you coming mam when are you coming for composition'. They're saying composition is their favourite subject. The class teachers are asking me what did you do (calls own name) they're writing beautifully right.

She is here talking about the kind of training that affects the teacher and effects change. The teacher is shown what to do and how to make application, and furthermore she is helped to see the logic, value and potential in what is being done. This kind of training also targets attitudinal change (I will speak more on this issue later) which should serve teachers well in the classroom as they become more positive about finding ways of tackling linguistic issues, and correspondingly this should affect student motivation positively. I am therefore saying that teacher training should incite them to positive action. They should not leave training feeling as did one teacher in Sweetland's study: "I had some linguistics before...I got what they were trying to say, but I didn't know what to do with it. They never explained how I was supposed to change..." (as cited in Godley et al., 2006: 34). As teachers, we need to know what to do with the information we are getting if it is to translate into beneficial practice. I do not believe that teachers should be told what to do, but in these sessions they should be helped to discover ways of using their knowledge to sharpen their skills in the language classroom. In this way the information becomes more meaningful, and teachers are more inclined to implement their own 'discoveries'. Emphasis should be primarily placed on application of knowledge in pedagogical training, as currently the training is too theory laden.

\subsubsection{Diversity Training}

There needs to be extensive and unconventional attitudinal training in the Eastern Caribbean for ELTs regarding diversity. We cannot hope that knowledge alone will change attitudes. In fact this training should directly target teacher language attitudes with the objective of showing up how they have impacted, are impacting, and will impact classroom practice. This has to be the kind of training that gets teachers to own up to their language prejudices and be appalled enough by them that they see no other alternative but seeking positive change. This training must tackle issues of linguistic diversity and inclusion, linguistic elitism and personal and professional fears. Indeed, this training should assist teachers in recognising that they will always encounter difficulties in teaching English because of the unique linguistic context of this region, but arguably, some are of their own making. English is not a foreign language in these territories, but by linguistic definition, neither is it a second language; but a second 
dialect. This cannot be changed, but a teacher's attitude towards linguistic diversity/variation in the classroom can. In an ideal world, life would be easier were we teaching a group of homogeneous students, but in the real world we do not. We might not even recognise that diversity is an issue in our context because most of our students look and sound alike, but diversity is so much more and sadly there is no training in place to illustrate this. Even when there is training, there is no guarantee that there will be access. For example, in the U.S. Godley et al (2006) lament that despite the fact that language informs every aspect of the teaching/learning dynamic, nearly $1 / 3$ of the teachers in the Language Arts profession have never taken a course in language diversity or Linguistics. Likewise, as Eastern Caribbean teachers of English, rather than being taught how to design lesson plans of inclusion, we are trained, covertly and overtly, to see learners as a homogeneous group who require generic training. The frustration comes because our expectations do not mirror the reality, and this is because the issue of linguistic diversity and variation is yet to be properly understood and addressed in these Caribbean contexts. In the words of Sapon-Shevin (2005): "To create inclusive classrooms, teachers must think about what they teach, how they teach, and how they structure interaction among students. Transmitting consistent messages about the positive nature of diversity and the need for inclusiveness means that all aspects of classroom life must reflect that commitment" (p. 46). Our teachers are incapable of achieving this, because neither are they fully aware of the issues of linguistic diversity in the classroom nor of its serious implications. Perhaps due to social moulding, we may very well be seeing the issue of diversity myopically, believing that it relates only to race and culture, and because the majority of our students are of the same race and culture, we do not see the issue as one of diversity. Still, the fact that students' language is different from the school's language and their level of exposure to the school's language outside of school will vary, must introduce an element of diversity/variation into our classrooms. Diversity/variation in our contexts may be primarily linguistic, so our attitudes must be modified to accept that diversity exists as a real challenge which must be addressed sooner rather than later.

Training programmes should do more than promote awareness of dialect diversity, they should draw up teachers' attitudes about it. I know that educating teachers about diversity will not result in some magical change, but I believe that awareness of, and reflection on this awareness might. This awareness and reflection could influence teachers' attitudes, by helping them to see the need to curb any prejudices that may interfere with their professional practice. Greenbaum (1985) expresses this well when he says: '[g]reater understanding may not eliminate prejudices, but it may serve to moderate them by making us aware of them and of their effects. We can learn to restrain our private prejudices from directing our public behaviour' (p. 5). This means that research into teacher attitudes and how it should inform teacher education programmes to meet teacher needs is important, for "[there] can be no significant innovation in education that does not have at its centre the attitudes of teachers" (Postman and Weingartner (1987: 33). Ball and Muhammad (2003) further explain that a course in language diversity should not just examine pertinent issues in the area, but it should aim to 'impact teachers' attitudes concerning language diversity' (p. 81), and therefore "teacher education grounded in sociolinguistic understandings of dialect diversity can help teachers develop productive pedagogical responses to students' language choices” (Godley et 
al., 2006: 30). Ball and Muhammad (2003) previously cited, actually found that such courses helped teachers become more tolerant of language variation in the classroom, and so they recommend that 'at least one course dealing with language variation, bilingualism, and global linguistic diversity... be required of all students in teacher education programs' (p. 81). Godley et al (2006) are very specific about how language variation/diversity should be addressed in such programmes. They cite three themes that should be included in any such course:

* Anticipating and overcoming resistance to dialect diversity

* Addressing issues of language, identity and power

* Emphasizing practical pedagogical applications of research on language variation.

\subsubsection{Reflective Training}

Training must be intricately bound up with self-reflection. This involves finding that delicate balance as a teacher trainer between what teachers bring to the training and with what they are expected to leave. Irvine (2003: 46) expresses it this way: 'Teachers bring to their work values, opinions, and beliefs; their prior socialization and present experiences, and their race, gender, ethnicity, and social class. These attributes and characteristics influence teachers' perceptions of themselves as professionals'. While it is always commendable that teachers want to act professionally on the job, teaching is one of those fields where one cannot hope to be professional by separating out the personal self. I have argued elsewhere that language teaching calls for a great deal of empathy to understand the struggles, frustrations, joys and accomplishments of finding one's voice in a language. As teachers, we find that empathy in the personal self. To shut off that self is tantamount to shutting off the learner (Denny, 2007). Reflective training therefore becomes necessary as part of the instructive process, as "[r]eflection enables teachers to examine the interplay of context and culture as well as their own behaviors, talents, and preferences" (Irvine, 2003: 76). A large part of the problem is that teachers are existing in the moment, simply present in the present attempting to cope with several classroom issues simultaneously. They are worn out, which does not always leave time for serious reflection. Guided reflection, provided through training, can help teachers start to address existing contradictions, and work at bringing them into alignment so as to ease some of their professional frustrations. Reflection means that teachers confront their views about language, language learning and teaching so that if there are gaps between what they believe and how their practice plays out, then they know they need to work on closing these gaps. It is true that teachers come with their prejudices, but as trainers we want them to leave with an understanding of why they bear these prejudices and how they can be detrimental to their practice, without telling them. Let them make the connections between their own theories and practices as part of their reflection.

\subsubsection{Non-Elitist Training}

In addressing issues of diversity we begin to challenge views of linguistic elitism (the standard is linguistically superior to the nonstandard). One way of addressing the issue of lack of tolerance of dialect diversity in classrooms is to address the misconceptions about 
language which give rise to elitist attitudes. Lippi-Green (1999) highlights some of these misconceptions:

* Not all languages equally express a full range of ideas

* English has no deficiencies when compared to other languages

* Grammaticality and communicative effectiveness are the same

* There is one valid variety of English

* Written and spoken language are the same or similar in function

* It is easy to think in an unfamiliar language

Teachers must be assisted in their training to understand in practical terms that language superiority is a social and not a linguistic construct; standard dialects are not linguistically better 'by any objective measures; they are socially preferred simply because they are...used by those who are most powerful and affluent in society' (Godley et al., 2006: 30). All languages are linguistically sound systems which meet the communicative needs of their speech communities. Non-standard dialects are different from standard dialects, but not deficient in relation to them. Some teachers may honestly not know this, and might in fact be confusing poor English grammar with native language interference, or normal language development with native language interference, so that the native language continues to be the chief offender in the language acquisition process in the teachers' mind; hence, the reason they want to banish it from the domain in which it can "contaminate" the "privilege and pure" school language. Training that tugs at the roots, until uprooted, of such socially imposed language attitudes, will eventually prove beneficial to our language education system, as we would no longer be battling with the heavy burden of social language bias along with all we attempt to juggle in the classroom.

\subsubsection{Training to Combat Fears}

A reliance on texts suggests a fear of self-reliance. We solve people's educational issues daily, but it appears that when it comes to fixing our own we are less confident in our own abilities to do so. Let us return to the issue of resources, something over which we do have a measure of control, and let me permit Strickland (1998) to have a say: "A teacher whose goal is to follow the textbook is a teacher with no goals at all' (p. 140). I would not say that our teachers have no goals, but that perhaps these goals do not always complement the goals of education or language learning. Our reliance on texts to the point that we see a lack as a major challenge implies that the language is academic, merely a subject on the curriculum, but by our actions and expressions we contend that students are not treating it as a mode of communication for life. If we do not treat it as we wish the students to, then therein lies the problem. In tying the language so closely to school texts and schooling, students see it as only important for that context. In my own experience of teaching teachers, I have found that many of them welcome help, but sometimes to the point where they want to be handed the answers to classroom problems on the proverbial platter. Perhaps, it is because they are exhausted mentally at having to think through lessons, details of the language, approaches to 
teaching the language and just managing the class. Nevertheless, this reliance on published texts, even when inadequate (culturally foreign), might indicate that teachers fear relying on their own abilities to create effective materials for classroom use. This is understandable for new teachers; still, teachers must see what they have to offer as a knowledgeable resource on which they and others can capitalize (Lieberman, 1995). Teachers must know that they are the best kind of material resource for their students. They know their students' needs and they certainly know what interests their students and what is culturally relevant. Why then sit back and wait for someone else to write their lives, when you could join in planning, writing and publishing culturally responsive materials? Apart from teaching, this is your next best contribution to your students and the system. You are the scholars and the best available resources in this profession.

\section{Conclusion}

As teachers of the perceived prestige language, we fear being labelled incompetent. After all, " $[\mathrm{t}]$ he essence of being an effective teacher lies in knowing what to do to foster pupils" learning and being able to do it" (Kyriacou, 2007: 1). It might help if we take the focus off us and shine the spotlight on our students. What do I mean? We need to start seeing our students as our most valuable clients. When they walk into our establishments they need not be troubled with the flaws behind the scenes. They simply should expect and get the best possible service from well-trained, qualified, and competent staff. It is true that in our transactions with them the systemic flaws can become apparent, but projecting those flaws on to the student will be nothing more than an attempt to protect self from severe criticism; which adds another layer to the problems. When we do not tackle the issues as they arise; when we shift blame; when we hide behind our own inadequacies; when we degrade our children and their language we add to the layers. They become an entangled mess of contradictions primarily because we, as teachers, are all in the system trying to save face in one way or another.

I strongly believe that it is not education and training that will make the significant difference in these language education scenarios, but confronting our associated fears will. As teachers, we must confront the fears that foster negative language attitudes, the fears that create communication barriers (DEF ears) and that give rise to contradictions (disparity between theory and practice). In facing our fears we acknowledge our linguistic deficiencies with the objective of turning them into strengths. We acknowledge the historical context which breeds this fear, acknowledge it as such - history from which much can be learned to help us move forward. As Eastern Caribbean ELTs we must actively and proactively manoeuvre our abilities, knowledge and practice so that they define us professionally. In confronting our fears of others exposing our deficiencies, we will seek ourselves to expose them, own them and correct them. This is the strategy which will quell our fears. Face those fears, address those fears and win over those fears. In confronting these fears we would have taken steps to listen to, acknowledge, understand and appropriately address the issues of DEF in Eastern Caribbean Language Arts classrooms, as we continually improve in becoming more tolerant, more egalitarian, more confident, more knowledgeable, more skilled and more proficient professionals. 


\section{References}

Ball, A., \& Muhammad, R. (2003). Language diversity in teacher education and in the classroom. In G. Smitherman \& V. Villanueva (Eds.), Language diversity in the classroom: From intention to practice (pp. 76-88). Carbondale, IL: Southern Illinois University Press.

Bartolomé, L. (1994). Teaching strategies: their possibilities and limitations. In B. McLeod (Ed.), Language and Learning: Educating Linguistically Diverse Students (pp. 199-223). Albany, NY: State University of New York Press.

Berliner, D. (2000). A personal response to those who bash teacher education. Journal of Teacher Education, 51(5), 358-371. http://dx.doi.org/10.1177/0022487100051005004

Brown, R. (1973a). Development of the first language in the human species. American Psychologist, 28(2), 97-106. http://dx.doi.org/10.1037/h0034209

Brown, R. (1973b). A first language. Cambridge, MA: Harvard University Press.

Campbell, D., Melenyzer, B., Nettles, D., \& Wyman Jr., R. (2000). Portfolio and performance assessment in teacher education. Boston, MA: Allyn \& Bacon.

Denny, S. (2002). We survived the inhumanity but do we still wear the shackles?: An investigation into teachers' attitudes towards Barbadian Dialect as a medium of instruction (Unpublished doctoral dissertation). University of Exeter, Exeter, England.

Denny, S. (2007). Fully facing facts: Teach the teachers then talk yuh talk. La Torre, 46, 519-544.

Denny, S. (2010). The ABCs of teacher language proficiency. In N. Faraclas, R. Severing, C. Weijer, E. Echteld, M. Hinds-Layne and E. Lawton de Torruella (Eds.), In a sea of heteroglossia: Pluri-lingualism, pluri-culturalism, and pluri-identification in the Caribbean (pp. 135-152). Williamstead, Curacao: Fundashon pa Planifikashon di Idioma.

Dulay, H., \& Burt, M. (1972). You can't learn without goofing: An analysis of children's second language 'errors'. Retrieved from eric.ed.gov/?id=ED066891

Dulay, H., \& Burt, M. (1974). Errors and strategies in child second language acquisition. TESOL Quarterly, 8(2), 129-136. Retrieved from eric.ed.gov/?id= EJ101096

Geertz, C. (1983). Local knowledge: Further essays in interpretive anthropology. New York, NY: Basic Books.

General Accounting Office. (2003). Report to Congressional Requesters. No child left behind Act: More information would help states determine which teachers are highly qualified (GAO-03-631). Washington, DC: U.S. General Accounting Office.

Godley, A., Sweetland, J., Wheeler, R., Minnici, A., \& Carpenter, B. (2006). Preparing teachers for dialectally diverse classrooms. Educational Researcher, 35(8), 30-37. http://dx.doi.org/10.3102/0013189X035008030 


\section{Macrothink}

Journal of Education and Training

ISSN 2330-9709

2016, Vol. 3, No. 1

Greenbaum, S. (1985). Issues and implications. In S. Greenbaum (Ed.), The English language today (pp. 1-5). Oxford, England: Pergamon.

Irvine, J. J. (2003). Educating teachers for diversity: Seeing with a cultural eye. New York, NY: Teachers College Press, Columbia University.

Kyriacou, C. (2007). Essential teaching skills. Gloucester, England: Nelson Thornes Ltd.

Lieberman, A. (1995). Practices that support teacher development. Phi Delta Kappan, 76(8), 591-596.

Lippi-Green, R. (1997). English with an accent: Language, ideology and discrimination in the United States. New York, NY: Routledge.

McLeod, B. (1994). Linguistic diversity and academic achievement. In B. McLeod (Ed.), Language and Learning: Educating Linguistically Diverse Students (pp. 9-44). Albany, NY: State University of New York Press.

Moll, L. (1992). Bilingual classroom studies and community analysis: Some recent trends. Educational Researcher, 21(2), 20-24. http://dx.doi.org/10.3102/0013189X021002020

National Council of Teachers of English. (1965). Language programs for the disadvantaged: The report of the NCTE task force on teaching English to the disadvantaged. Champaign, IL: NCTE.

Postman, N., \& Weingartner, C. (1987). Teaching as a subversive activity. New York, NY: Dell.

Sapon-Shevin, M. (2005). Ability differences in the classroom: Learning in inclusive classrooms. In D. Byrnes \& G. Kieran (Eds.), Common bonds: Anti-bias teaching in a diverse society. ( $3^{\text {rd }}$ ed.). (pp. 37-51). Olney, MD: Association for Childhood Education International.

Scott, J., \& Smitherman, G. (1985). Language attitudes and self-fulfilling prophecies in the elementary school. In S. Greenbaum (Ed.), The English language today (pp. 302-314). Oxford, England: Pergamon.

Smart, G. (1998). Mapping conceptual worlds: Using interpretive ethnography to explore knowledge-making in a professional community. The Journal of Business Communication, 35(1), 111-127. http://dx.doi.org/10.177/002194369803500107

Strickland, G. (1998). Bad Teachers: The Essential Guide for Concerned Parents. New York, NY: Pocket Books.

Winch, C., \& Gingell, J. (1994). Dialect interference and difficulties with writing: An investigation in St. Lucian primary schools. Language and Education, 8(3), 157-182. http:dx.doi.org/10.1080/09500789409541388 


\section{Appendix 1 (Questionnaire)}

As regards the project on teacher proficiency, which we previously discussed, I am now formally asking for your involvement by requesting that you fill in the questionnaire as truthfully as possible. Your identity will remain anonymous. I thank you in advance for your participation in this project.

1. Tick one of the following. Age: under $25 \quad 26-35 \quad 36-45 \quad 45+$ (over 45)

2. How long have you been teaching?

3. Country of birth.

4. Country in which you grew up.

5. Country where you teach....

6. Do you teach English?.... If yes, at what level? (E.g. primary).

7. What is your native language?

8. If your native language is not English, which language do you use most often?

9. What language do you primarily use in the classroom?

10. Why this language?

11. Complete this sentence. I am.... .in my use of the English language.

12. What grade did you receive in the regional examination in English language at secondary school (e.g. CXC, GCSE)

13. List at least 5 difficulties you find in teaching the English language (only to be answered if you teach English). List the most difficult first.

14. In your experience what are the most common errors students make when attempting to write the English language (list at least three even if you do not teach English)

a.

b.

15. Have you ever seen colleagues use incorrect English grammar in the classroom?

If yes, what did you do? c.

d.

16. If no, what do you think you would have done had you been confronted with this situation? 


\section{Macrothink}

17. Make some comments on your colleagues' (those who teach with you) proficiency in the English language.

18. What strategies would you put in place to deal with the falling standards of the English language in schools?

Thank you. Any additional comments can be written at the back. Please ensure that you make clear which question you are answering.

\section{Appendix 2 (Unstructured Interview schedule)}

1. Do you ever use dialect in the classroom? Why, or why not?

2. How proficient are you in English? Why do you say this?

3. Do you see your colleagues as proficient in the English language? Why have you answered this way?

4. Have you ever seen or heard colleagues make errors in English in the classroom? What have you done about it if this is so?

5. How can teachers be helped to become more proficient, if they aren't already?

\section{Copyright Disclaimer}

Copyright reserved by the author(s).

This article is an open-access article distributed under the terms and conditions of the Creative Commons Attribution license (http://creativecommons.org/licenses/by/3.0/). 